\title{
Production of attaching-effacing lesions in ligated large intestine loops of 6-month-old sheep by Escherichia coli 0157:H7
}

\author{
ANDREW D. WALES, FELICITY A. CLIFTON-HADLEY*, ADRIAN L. COOKSON*, \\ MICHAEL P. DIBB-FULLER*, ROBERTO M. LARAGIONE*, GEOFFREY R. PEARSON and \\ MARTIN J. WOODWARD*
}

Department of Pathology and Microbiology, University of Bristol School of Veterinary Science, Langford, Bristol BS40 5DU and *Department of Bacterial Diseases, Veterinary Laboratories Agency, Woodham Lane, New Haw, Addlestone, Surrey KT15 3NB, UK

\begin{abstract}
Shiga-toxigenic Escherichia coli O157:H7 (STEC 0157:H7) is associated with potentially fatal human disease, and a persistent reservoir of the organism is present in some farm animal species, especially cattle and sheep. The mechanisms of persistent colonisation of the ruminant intestine by STEC O157:H7 are poorly understood but may be associated with intimate adherence to eukaryotic cells. Intimate adherence, as evidenced by induction of attaching-effacing (AE) lesions by STEC O157, has been observed in 6-dayold conventional lambs after deliberate oral infection but not in older animals. Thus, the present study used a ligated intestinal loop technique to investigate whether STEC 0157:H7 and other attaching-effacing $E$. coli may adhere intimately to the sheep large intestinal mucosa. To do this, four STEC O157:H7 strains, one STEC O26:K60:H11 and one Shiga toxin-negative $E$. coli $0157: H 7$ strain, suspended in either phosphate-buffered saline or Dulbecco's modified Eagle's medium, were inoculated into ligated spiral colon loops of each of two lambs. The loops were removed $6 \mathrm{~h}$ after inoculation, fixed and examined by light and electron microscopy. AE lesions on the intestinal mucosa were produced by all the inoculated strains. However, the lesions were sparse and small, typically comprising bacterial cells intimately adhered to a single enterocyte, or a few adjacent enterocytes. There was little correlation between the extent of intimate adherence in this model and the bacterial cell density, pre-inoculation growth conditions of the bacteria or the strain tested.
\end{abstract}

\section{Introduction}

Shiga-toxigenic Escherichia coli (STEC) O157:H7 is found world-wide and is a leading cause of human disease [1-3]. The release of Shiga toxin in the human bowel following ingestion is believed to be central to the pathogenesis of the associated diseases. Locally, haemorrhagic colitis is induced [4], and damage to the systemic vasculature, especially in the kidney, may lead to the haemolytic-uraemic syndrome [5], which can be fatal. Moreover, STEC 0157:H7 can form an intimate association, termed the attaching-effacing (AE) lesion,

Received 2 April 2002; revised version received 4 May 2002; accepted 13 May 2002.

Corresponding author: Professor M. J. Woodward (e-mail: m.j.woodward@vla.defra.gsi.gov.uk). which has been observed in vitro on HEp-2 and other eukaryotic cell lines $[6,7]$, on the mucosa of bovine and human intestine in organ culture $[8,9]$, and experimentally in vivo on the intestinal mucosa in various animal species [10-12] including cattle [13] and sheep [14]. However, mucosal associations, including AE lesions, have not been reported in naturally persistently colonised, ruminating cattle or sheep, and the role of adherence in natural colonisation of animals by STEC O157:H7 is unknown. The AE capability is encoded on a chromosomal pathogenicity island termed the locus for enterocyte effacement (LEE) [15]. The role of the AE lesion in human disease is undetermined. Several other attributes which may be associated with virulence such as the haemolysin, secreted serine protease, the bifunctional catalase-peroxidase KatP and the EHEC type II secretion system, are encoded by a large (60 MDa) plasmid by most STEC 
O157:H7 [16], although, its role remains to be fully elucidated [7].

In contrast to man, natural exposure of farm animals to STEC 0157:H7 has not been reported to be associated with disease, but prolonged carriage may be observed in ruminants [17-20]. The carriage of STEC O157:H7 by ruminants, especially cattle and sheep, is important because these appear to be a primary source of contamination of human foodstuffs [21, 22]. Early studies suggested that the organism was widespread [23], a finding confirmed in a number of prevalence studies that employed serological [24] and improved bacteriological methods $[25,26$, and G. Paiba, personal communication]. Some longitudinal studies suggest that excretion of the organism by individual animals on infected premises is typically transient and may be intermittent, but that a herd's positive status, as determined by faecal screening, tends to be maintained over time [17, 18, 27, 28]. In sheep, the natural carriage and excretion of STEC O157:H7 on-farm has been documented [20, 29].

In experimental studies, adult cattle inoculated orally with STEC O157:H7 excreted the inoculated strain for up to 14 weeks $[30,31]$ and adult sheep for up to 2 months [32,33]. The susceptibility to STEC O157: $\mathrm{H} 7$-induced AE lesions has been demonstrated in 6day-old conventional lambs [14] and colostrum-deprived neonatal calves $[13,34]$ given $10^{9}$ cfu orally in both studies, and in weaned calves of up to 4 months of age after starvation for $48 \mathrm{~h}$ and inoculation with $10^{10} \mathrm{cfu}$ by stomach tube [35]. Dean-Nystrom et al. $[34,35]$ have suggested that AE lesions may not be detected below a threshold concentration $\left(10^{5.5}-\right.$ $10^{6} \mathrm{cfu} / \mathrm{g}$ ) of STEC O157:H7 in the intestine.

The ligated intestinal loop technique has been established as a method for observing the effects of a locally administered agent on a particular region of the intestine in a number of species [36] and was first utilised for attaching-effacing $E$. coli (AEEC) by Moon et al. [37]. The possibility of creating multiple loops in a single animal permits comparison of different agents within the same animal, and minimises the number of experimental animals required. These qualities make the technique attractive for observing the effects of various STEC O157:H7 strains in the ruminant intestine, and in particular to search for $\mathrm{AE}$ lesions in a well-defined area which has been subjected to a high density bacterial inoculum. Stevens et al. [38] demonstrated the enteropathogenicity of STEC O103:H2 and O157:H7 in ligated mid-ileal loops in 7-day-old gnotobiotic and 25-30-day-old conventional calves, a species already shown to be susceptible to AE lesion formation induced by STEC after deliberate inoculation [9, 13, 34, 35]. We have shown previously that STEC O157:H7 induces sparse AE lesions that are small, typically seen to cover 3 or 4 but occasionally up to 15 adjacent enterocytes in a section, after oral inoculation of 6-day-old conventional lambs but not older animals. Thus, the purpose of this study was to use the ligated colon loop of 6-month-old sheep to investigate whether they may be susceptible to $\mathrm{AE}$ lesion formation induced by four STEC O157:H7 strains, one non-toxigenic O157:H7 strain and an O26:K60:H11 strain.

\section{Materials and methods}

\section{Bacterial strains and inocula}

Four STEC O157:H7 strains and one Shiga toxinnegative E. coli O157:H7 strain were used. Strains 218 and 222 were isolated during field surveys in cattle, and strains EC157 and 140065 from human sources were supplied by the Public Health Laboratory Service, Colindale, London. PCR was used, as described previously [14], to detect virulence genes. Strains 218 and EC157 possessed both stx 1 and stx2, and strains 222 and 140065 possessed stx 2 only. These four strains and strain NCTC12900, a Shiga toxin-negative E. coli O157:H7 obtained from the National Collection of Type Cultures (Colindale, London), all possessed the locus for enterocyte effacement (LEE) and plasmid, pO157, typical of the serotype.

There are currently no characterised naturally occurring strains known to form AE lesions in sheep. In an effort to validate the technique in respect of the formation of AE lesions, an STEC O26:K60:H11 strain (EC 1537) was used as a comparative inoculum. This strain had an established spontaneous AE capability in natural disease in cattle, having been isolated from the faeces of a dysenteric heifer in which $\mathrm{O} 26$-associated $\mathrm{AE}$ lesions were detected [39]. This organism possessed genes encoding stx 1 and 2, the locus for enterocyte effacement (LEE), the enterohaemolysin and a serine protease [39].

Bacterial strains were grown in Luria-Bertani broth overnight in a shaking incubator at $37^{\circ} \mathrm{C}$, harvested by centrifugation and resuspended in phosphate-buffered saline (PBS, $\mathrm{pH} 7.2$ ) to give a viable count of $c$. $2.5 \times 10^{8} \mathrm{cfu} / \mathrm{ml}$. An alternative preparation was used to stimulate expression of LEE-encoded proteins before inoculation. For this, $200 \mu \mathrm{l}$ of an overnight culture grown as above were inoculated into $20 \mathrm{ml}$ prewarmed Dulbecco's modified Eagle's medium (DMEM) and incubated aerobically for $6 \mathrm{~h}$ at $37^{\circ} \mathrm{C}$ in air with $\mathrm{CO}_{2}$ $5 \%$. The viable count of bacteria in each strain preparation was determined by standard methods (Table $1)$.

\section{HEp-2 cell adherence and fluorescent actin staining (FAS)}

Adherence assays of $0157: \mathrm{H} 7$ strains to HEp-2 cells were performed by the methods of Dibb-Fuller et al. [40]. FAS reactions on HEp-2 monolayers were 
Table 1. Details of occurrence of AE lesions in histological sections of ligated spiral colon loops of two lambs inoculated with E. coli $\mathrm{O} 157: \mathrm{H} 7$ and $\mathrm{O} 26: \mathrm{H} 11$

\begin{tabular}{|c|c|c|c|c|c|c|c|c|c|}
\hline \multirow{2}{*}{$\begin{array}{l}\text { Lamb } \\
\text { no. }\end{array}$} & \multirow[b]{2}{*}{ Serotype } & \multirow[b]{2}{*}{ Strain } & \multirow[b]{2}{*}{ Loop } & \multirow{2}{*}{$\begin{array}{l}\text { Inoculum } \\
\text { dose } \\
\left(\times 10^{8} \mathrm{cfu}\right)\end{array}$} & \multicolumn{2}{|c|}{$\begin{array}{l}\text { Number of AE } \\
\text { lesions (number of } \\
\text { sections examined) }\end{array}$} & \multirow{2}{*}{$\begin{array}{l}\text { Maximum } \\
\text { lesions } \\
\text { per } \\
\text { section }\end{array}$} & \multirow{2}{*}{$\begin{array}{l}\text { Total } \\
\text { positive } \\
\text { sections }\end{array}$} & \multirow{2}{*}{$\begin{array}{l}\text { Total } \\
\text { AE } \\
\text { lesions }\end{array}$} \\
\hline & & & & & $\mathrm{H} \& \mathrm{E}$ & Ipx & & & \\
\hline \multirow[t]{6}{*}{1} & O26:H11 & EC 1537 & A & 5.0 & $8(18)$ & $11(13)$ & 7 & 10 & 19 \\
\hline & O157:H7 & 218 & B & 8.3 & $6(21)$ & $20(14)$ & 7 & 13 & 26 \\
\hline & & 222 & $\mathrm{C}$ & 4.5 & $0(18)$ & 0 (12) & 0 & 0 & 0 \\
\hline & & 140065 & $\mathrm{D}$ & 4.6 & $1(21)$ & $0(10)$ & 1 & 1 & 1 \\
\hline & & EC 157 & $\mathrm{E}$ & 6.3 & 0 (16) & $3(12)$ & 2 & 2 & 3 \\
\hline & & NCTC 12900 & $\mathrm{~F}$ & 5.7 & $0(22)$ & $0(12)$ & 0 & 0 & 0 \\
\hline \multirow[t]{6}{*}{2} & O26:H11 & EC 1537 & G & 12.3 & $0(16)$ & $2(14)$ & 1 & 2 & 2 \\
\hline & O157:H7 & 218 & $\mathrm{H}$ & 12.7 & $4(18)$ & $5(18)$ & 2 & 8 & 9 \\
\hline & & 222 & I & 14.7 & 0 (15) & $5(14)$ & 5 & 1 & 5 \\
\hline & & 140065 & $\mathbf{J}$ & 10.6 & $3(21)$ & $4(20)$ & 1 & 7 & 7 \\
\hline & & EC 157 & $\mathrm{~K}$ & 10.3 & $0(16)$ & $2(14)$ & 2 & 1 & 2 \\
\hline & & NCTC 12900 & $\mathrm{~L}$ & 9.3 & $3(18)$ & $5(16)$ & 2 & 5 & 8 \\
\hline
\end{tabular}

H\&E, haematoxylin and eosin stain; Ipx, immmunoperoxidase stain.

observed following the methods of Knutton et al. [41] as described by Dibb-Fuller et al. [40].

\section{Animal procedures}

Two 6-month-old cross-bred lambs were used. Freedom from detectable E. coli O157 excretion was demonstrated by examining faeces from each lamb on three separate occasions before surgery. The faeces were then cultured selectively for E. coli O157:H7 on CHROMagar (CHROMagar Microbiology, France) after preenrichment and immunomagnetic separation, as described previously [14]. After shearing the ventral abdomen and overnight feed withdrawal, sedation and anaesthesia were induced by methods described previously [42]. Briefly, each lamb was premedicated with xylazine (Rompun $2 \%$, Bayer) $0.2 \mathrm{mg} / \mathrm{kg}$ given by deep intramuscular injection, and then anaesthetised with a combination of diazepam (Valium, Roche) and ketamine (Ketaset, Fort Dodge) given intravenously. After intubation, anaesthesia was maintained by inhalation with isofluorane in oxygen via a circle circuit. During anaesthesia, lactated Ringer's solution was infused intravenously. Anaesthetic monitoring included measurement of rectal temperature, arterial blood pressure, $\mathrm{pO}_{2}, \mathrm{pCO}_{2}$ and an electrocardiograph. A ventral midline laparotomy was performed by an aseptic surgical technique and the spiral colon was exteriorised. Twelve ligated intestinal loops, each $c$. $10 \mathrm{~cm}$ long and separated by a short intervening segment, were created by tying pairs of encircling braided nylon ligatures around the spiral colon, and preserving the mesenteric blood supply to each segment. A 2-ml volume of inoculum containing either a single bacterial strain in $\operatorname{PBS}\left(c .5 \times 10^{8} \mathrm{cfu}\right)$ or $\operatorname{DMEM}\left(c .1 .2 \times 10^{9} \mathrm{cfu}\right)$, or the carrier medium alone, was then introduced into each loop by transmural injection with a 25 -gauge needle. The injection site was sealed on the serosal surface by thermocautery. Alternate loops were inoculated with bacteria, and the intervening loops served as controls without introduced bacteria. In lamb 1, the carrier medium was PBS and in lamb 2 it was DMEM. The relative position of each inoculum from proximal to distal colon followed the alphabetical sequence given in Table 1, and was the same for each lamb.

After inoculation, the intestine was replaced in the abdomen and the laparotomy incision was closed with sutures. The animal was maintained under anaesthesia in dorsolateral recumbency, with venting of ruminal gas via a paracostal rumenostomy. The ligated intestinal segments were re-exteriorised $6 \mathrm{~h}$ after inoculation and excised for fixation. The animal was then killed with pentobarbitone.

All procedures complied with Animals (Scientific Procedures) Act 1986 and were performed under Home Office Licence 70/4987.

\section{Histological studies}

After removal from the animal, the intestinal loops were opened and placed immediately in neutral buffered formalin $10 \%$ and fixed for at least $24 \mathrm{~h}$. Representative pieces were processed routinely to paraffin wax, and three-to-five tissue blocks were prepared from each loop. Multiple $4-\mu \mathrm{m}$ sections, comprising several levels from each block, were stained with haematoxylin and eosin (H\&E). Selected sections from lamb 2 were also stained by the Warthin-Starry technique.

\section{Immunohistochemistry}

Indirect immunoperoxidase staining was done on multiple sections from all inoculated loops. Briefly, wax-embedded $4-\mu \mathrm{m}$ sections were incubated with normal goat serum $20 \%$ and then labelled with primary polyclonal ' $\mathrm{O}$ ' antisera raised in rabbits. Two antisera 
that were used specifically labelled O157 and O26 organisms respectively. Control sections of agar-embedded E. coli $\mathrm{O} 157$ and O26, plus a control normal rabbit serum, were used to verify specificity. For light microscopy, a goat anti-rabbit bridge antibody (SigmaAldrich), rabbit peroxidase-antiperoxidase (PAP) complex (Dako) and diaminobenzidine (Sigma-Aldrich) were then applied sequentially. The sections were counterstained with Mayer's haematoxylin.

\section{Electron microscopic studies}

Small tissue pieces were excised from the paraffin wax blocks at sites likely to contain AE lesions, as identified by light microscopic examination. The excised tissue was dewaxed, rehydrated, post-fixed in osmium tetroxide and embedded in epoxy resin. Thin sections were stained with lead citrate and uranyl acetate and examined in a Philips 201 transmission electron microscope.

\section{Results}

\section{Adherence properties of bacterial strains}

The wild-type STEC O157:H7 and O26 strains and the Shiga toxin-negative O157:H7 strain adhered in similar numbers and generated actin re-arrangements characteristic of the AE lesion on HEp-2 monolayers, as evaluated by quantitative culture and the 6-h FAS test, respectively (data not shown).

\section{Macroscopic findings}

After removal from the animal, the ligated intestinal loops were hyperaemic and often mildly oedematous on the serosal aspect. The luminal contents were mucoid and frequently bloodstained. Loops were of normal external diameter and no differences in respect of intestinal wall colour, thickness and oedema, and of the appearance of intestinal contents were seen between control and test loops.

\section{Histological studies}

When measured macroscopically, the light microscope sections ranged in length from $11 \mathrm{~mm}$ to $59 \mathrm{~mm}$. Preservation of the mucosa was generally good, with only one loop (L) exhibiting detachment of short sections of the epithelium. A total of $82 \mathrm{AE}$ lesions was found in H\&E sections in 10 of the 12 loops inoculated with bacteria (Table 1). Forty-five of the lesions were observed in loops $\mathrm{A}$ and $\mathrm{B}$ that were inoculated with PBS-prepared inocula of the O26: K60:H11 strain and STEC O157:H7 strain 218, respectively, whereas 11 lesions were observed in loops $\mathrm{G}$ and $\mathrm{H}$ that were inoculated with DMEM-prepared inocula of these two strains, respectively. Fewer AE lesions were observed in loops inoculated with O157:H7 strains 222, 140065, EC157 and NCTC12900 prepared in PBS than in DMEM (Table 1). No lesions were observed in control loops. Typically, the lesions were small in that they covered one enterocyte or a few adjacent enterocytes (Fig. 1), with individual bacteria clearly distinguishable. Some lesions were found on detaching enterocytes (Fig. 2), although only in loop D was this exclusively the case.

The epithelial morphology appeared abnormal in 4 of 12 loops in lamb 1 and 11 of 12 loops in lamb 2. The mucosal surface in affected loops showed a ragged profile in a multifocal pattern. In lamb 2, this was often accompanied by rounding up and detachment of

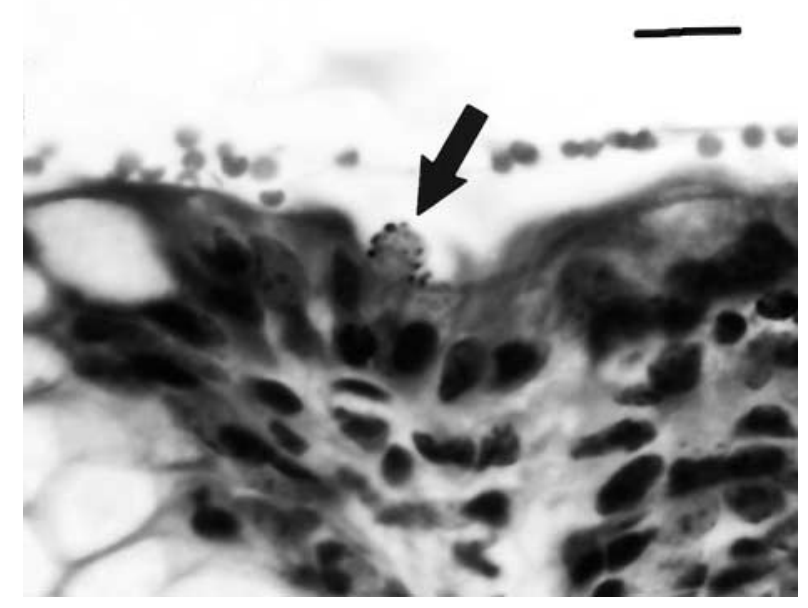

Fig. 1. Loop A, E. coli O26:H11. Attaching-effacing lesion (arrow). Bacteria are closely adherent to the apical membrane of an enterocyte, which protrudes above the intestinal surface. $\mathrm{H} \& \mathrm{E}, \mathrm{bar}=8 \mu \mathrm{m}$.

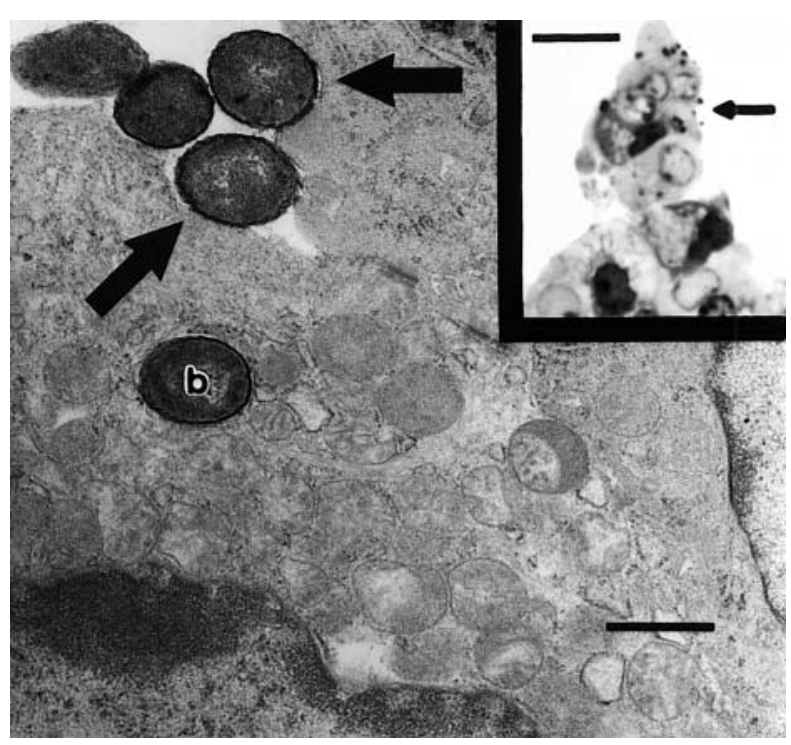

Fig. 2. Loop H, E. coli O157:H7. Attaching and effacing bacteria (arrow) are present on two adjacent, degenerating enterocytes. There is also possible invasion of one of the enterocytes by a bacterium (b). Electron micrograph, bar $=750 \mathrm{~nm}$. Inset: Degenerating and detaching enterocytes are colonised by bacteria (arrow). Toluidine blue-stained resinembedded section. Light micrograph, bar $=10 \mu \mathrm{m}$. 
enterocytes singly and in small clusters. There was no histological evidence that the thermocautery procedure damaged the mucosa. In lamb 2, small foci of epithelial necrosis were present in two control loops. A number of other histological features, including focal mucosal haemorrhage, neutrophilic serositis, and apoptosis in mucosa-associated lymphoid tissue, were seen commonly in both inoculated and control loops. In loops $\mathrm{L}, \mathrm{K}$ and $\mathrm{J}$ in lamb 2, localised colonisation of the subepithelial lamina propria by bacteria was evident in some areas of epithelial erosion. In loop E, a modest increase in the number of neutrophils in the lamina propria and several foci of neutrophil migration across the luminal epithelium were seen. In lamb 2, both inoculated and control loops contained moderate to large numbers of slender organisms of spirochaetal or Campylobacter-like morphology, occupying crypts and the intestinal lumen. Loose aggregations of such organisms were frequently present on the mucosal surface (Fig. 3), but there was no evidence that these organisms were attached to or invading the host intestinal wall, and there was no specific association with areas of epithelial abnormality. These bacteria stained positively with a Warthin-Starry silver stain.

\section{Immunohistochemistry}

The PAP stain proved sensitive and specific when the primary antisera for $\mathrm{O} 157$ and $\mathrm{O} 26$ were used on control sections of $\mathrm{O} 157$ and $\mathrm{O} 26$ organisms. AE lesions were found in five of the six loops in which lesions were detected in H\&E sections. Furthermore, $\mathrm{AE}$ lesions were found in four loops in which such lesions had not been detected in H\&E sections (Table

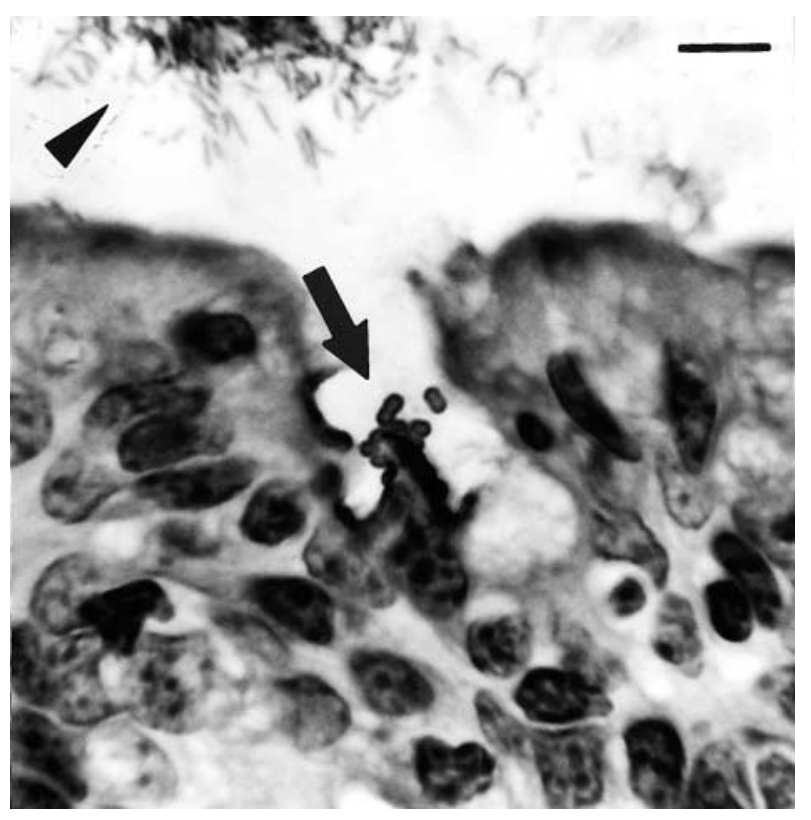

Fig. 3. Loop J, E. coli O157:H7. Attaching-effacing lesion (arrow). The mucosa shows a depression lined with closely adherent bacteria. An aggregation of spirochaetes, stained with Mayer's haematoxylin, is present in the lumen (arrowhead). O157 immunoperoxidase, bar $=8 \mu \mathrm{m}$.
1). The adherent bacteria were shown to be antigenically $\mathrm{O} 157$ (Fig. 3) or $\mathrm{O} 26$, as appropriate to the inoculum. In a number of loops, single positively staining bacteria were seen lying on the mucosal surface. The nature of the attachment, if any, of these single organisms to the host cells was uncertain. Thus, the recording of an $\mathrm{AE}$ lesion required the identification of a cluster of two or more positively staining bacteria in close apposition to the mucosa, i.e., evidence of multiple attached organisms in a single focus.

Many bacteria that expressed the $\mathrm{O} 157$ antigen were detected in the subepithelial lamina propria of the three loops $(\mathrm{L}, \mathrm{K}, \mathrm{J})$ in which lamina proprial colonisation had been detected in H\&E sections, and also in loop I.

\section{Electron microscopic studies}

Nine pieces of tissue were processed, seven from loops demonstrating light microscopic evidence of $\mathrm{AE}$ lesions and two from an area of lamina proprial colonisation. Three specimens yielded sections containing attaching-effacing bacteria. These were: two from loop A, containing E. coli O26 (Fig. 4) and one from loop H containing E. coli O157:H7 (Fig. 2). Both the preparations from areas showing lamina proprial colonisation contained bacteria, which in one area included curved or spiral forms (Fig. 5). In one preparation, organisms were present in areas of haemorrhage, and around and within the basal portions of crypt cells. In the other, bacteria were seen within a goblet secretory cell and in a vacuole within a polymorphonuclear neutrophil, the latter indicating active phagocytosis of bacteria within the tissues.

\section{Discussion}

The primary aim of this study was to assess whether STEC O157:H7 could induce AE lesions in the older

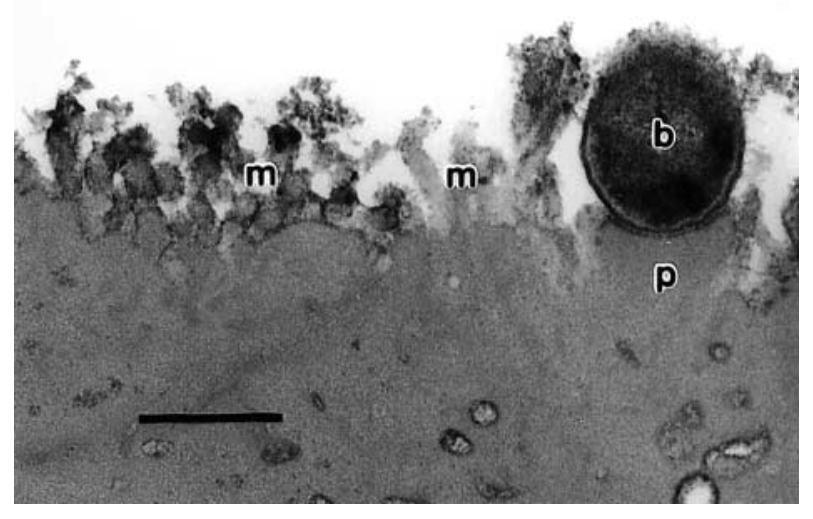

Fig. 4. Loop A, E. coli O26:H11. Attaching-effacing lesion. Microvilli (m) are effaced around a pedestal (p) to which a bacterium (b) is intimately attached. Electron micrograph, bar $=500 \mathrm{~nm}$. 


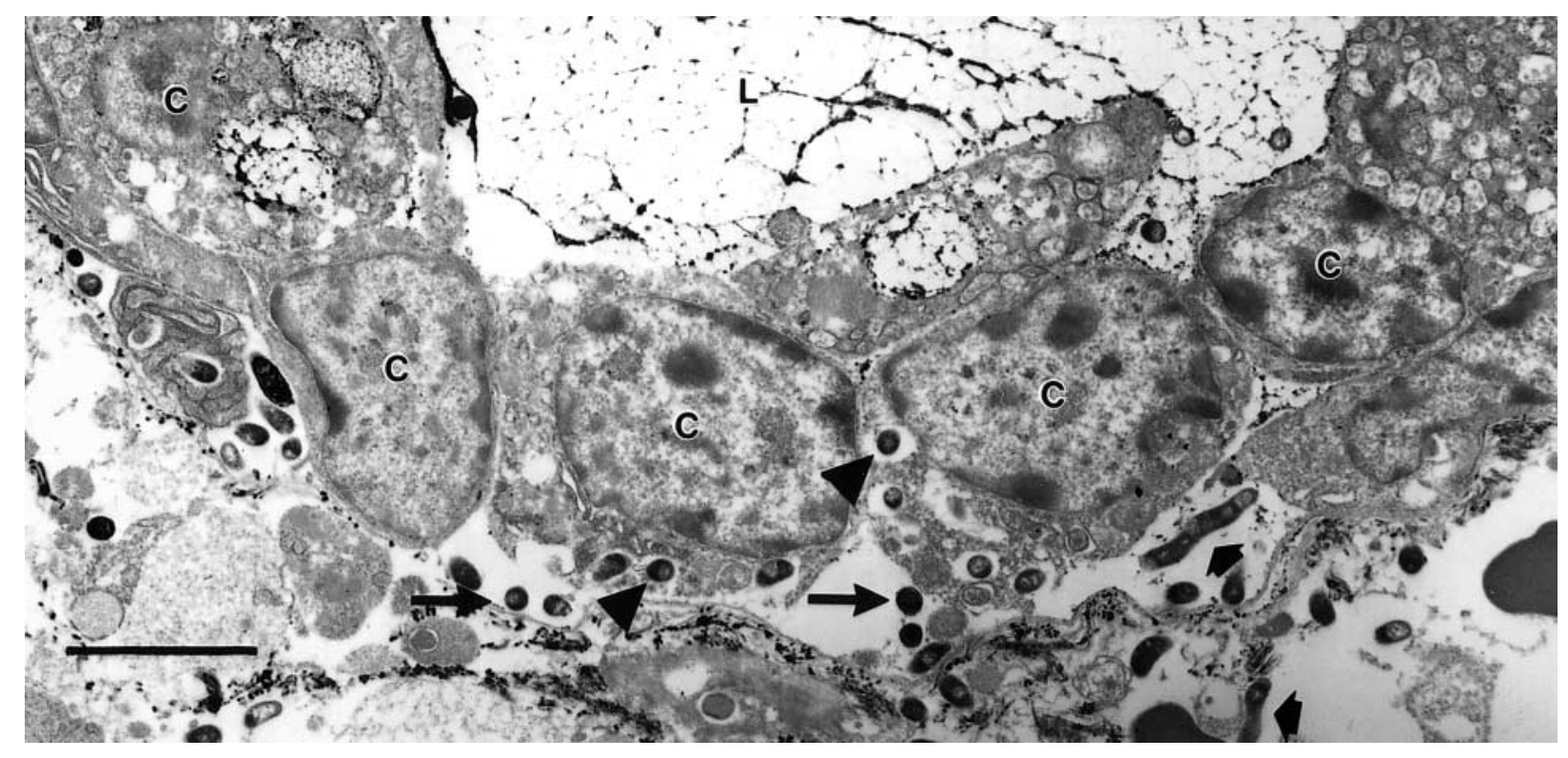

Fig. 5. Loop K, E. coli O157:H7. Intestinal crypt. Bacteria are present beneath (long arrows) and apparently within (arrowheads) crypt epithelial cells (C). Structures resembling spirochaetes or Campylobacter (short arrows) are also present in the lamina propria. L, crypt lumen. Electron micrograph, bar $=4 \mu \mathrm{m}$.

(6-month-old) animal. Oral inoculation of 6-month-old conventional lambs with STEC O157:H7 was not associated with the induction of AE lesions attributable to these organisms [43]. However, minute and sparse AE lesions were induced by STEC O157:H7 given orally to 6-day-old conventional lambs [14] which suggested that sheep are a susceptible species for AEmediated adhesion by STEC O157:H7 and possibly other AE organisms, as has been shown in cattle [44]. This study has demonstrated unequivocally that $\mathrm{AE}$ lesions were induced within $6 \mathrm{~h}$ when $0157: \mathrm{H} 7$ and O26:K20:H11 organisms were introduced to ligated colon loops of 6-month-old sheep. The spiral colon was used because STEC O157:H7 has formed lesions in the colon of calves [13,35] and lambs [14], and because it is the most readily manipulated and ligated part of the colon, by virtue of its mesenteric attachments and calibre. Furthermore its length, in comparison with other sections of the large intestine, allows the number of loops that can be created per animal to be maximised. The 6-h incubation time was chosen to give the inoculated organisms adequate time to form AE lesions, based upon the confirmatory FAS staining performed in vitro with these strains [41]. Preservation of the mucosa was adequate for $6 \mathrm{~h}$, but changes that may have been caused by circulatory compromise include the morphological alterations to the mucosa, observed in both control and test loops, and the limited mucosal haemorrhage.

Induction of the LEE locus by pre-growth of the STEC O157:H7 inocula in DMEM has been established for EPEC [45] and for EHEC [46]. Also, Dean-Nystrom et al. $[34,35]$ postulated that a critical bacterial cell density was required for lesion detection. However, in this study there seemed to be little positive correlation between LEE induction or increased bacterial cell density (albeit only over a four-fold range) and the numbers of lesions formed. For three strains (O26: K60:H11 strain EC1537 and STEC O157:H7 strains 218 and EC157), more lesions were detected when the inoculum used was at the lower density and was not induced for LEE. Thus, from the present data it seems likely that innate properties of the strains themselves and the local environment within the ligated gut loop may be more influential in the outcome of the bacterium-host interaction. For example, although both sheep were shown to be excreting no detectable strain O157 before the experiment, no account has been taken of the immune status of either animal used. Whereas the variation in bacterial numbers in the inoculum might have contributed to differences in the incidence of lesions, there was no clear correlation between the two.

A further factor confounding the detailed comparison of lesion numbers was the occurrence of clusters of lesions. These may have substantially, and perhaps artificially, elevated the number of lesions counted for a particular loop, against a lower background incidence. The incidence of sections showing multiple lesions was higher than might be expected if the lesion distribution was random, but the clusters of lesions seen in some loops were not associated with any visible predisposing features, such as mucosal damage. These clusters may reflect a locally increased density of luminal organisms, or possibly some host factor. Whether the bacteria grew within the ligated loop during the course of the experiment was not tested, and whether STEC O157: $\mathrm{H} 7$ ever reaches the luminal density used in this study during natural exposure is questionable.

There was no evidence of a loop-dilating effect of any inoculum, or of morphological alterations specifically 
associated with an STEC inoculum. The effect of Shiga toxin upon the bowel has been shown to vary between species $[47,48]$, and this includes changes observed in ligated loops $[49,50]$. It is consistent with the observed lack of clinical disease in naturally [20,29] and experimentally [32, 33, 43, 51] STEC-colonised sheep that the ovine colon appeared to be resistant to Shiga toxin-induced changes for the 6-h exposure used in the present study. Recent evidence indicates that Shiga toxins bind $\mathrm{Gb} 3$ receptors of the bovine intestinal epithelium and this may trigger host signal transduction responses that may modulate colonisation in this host [52]. Although in a short-term study, a Shiga toxinnegative E. coli $\mathrm{O} 157: \mathrm{H} 7$ strain was shown to colonise the bovine large intestine in lower numbers than a toxigenic O157:H7 strain [35], there is no evidence in the literature or from the present study that Shiga toxins are directly involved in the formation of $\mathrm{AE}$ lesions. In the present study, the elaboration of the Shiga toxins was not assessed and the potential effects on the host, that may be time-related, were not observed within the 6-h incubation period.

The sensitivity of H\&E and immunoperoxidase staining techniques for the detection of $\mathrm{AE}$ lesions in the present study appeared to be broadly similar. However, other workers [13] have found immunostaining to be the more sensitive method for detecting STEC O157:H7 AE lesions in bovine intestine. The advantages of immunostaining include the relatively easy detection of lesions, and the highlighting and identification of organisms of a specific serogroup or species elsewhere in the tissue, perhaps in unexpected locations. Electron microscopy, although hampered by the size and scarcity of the lesions, confirmed the nature of the characteristic AE-type light microscope lesions for both $\mathrm{O} 157$ and $\mathrm{O} 26$ organisms.

The identity of the numerous slender, spiral organisms seen in crypts and at the mucosal surface in lamb 2 is unknown, but Campylobacter-like organisms have been seen on the mucosa of sheep naturally infected with $C$. fetus [53]. Although there was no evidence for associated pathological change, these organisms remain a potential confounding factor when comparing data from the two lambs, and further studies comparing inoculation regimens within the same animal would be required to address this aspect. The present data are insufficient to speculate about a possible role of these organisms in colonisation by E. coli $\mathrm{O} 157: \mathrm{H} 7$ and other AE bacteria.

The bacterial colonisation of the lamina propria in lamb 2 did not correlate specifically with the presence of AE lesions but was associated with the inoculated strain O157 organisms, of both toxigenic and nontoxigenic strains. Colonisation of the lamina propria in animals inoculated experimentally with STEC O157: H7 has been reported in the caeca of chicks at 14 and 28 days post-inoculation (p.i.) [10] and of gnotobiotic piglets at 5 days p.i. [54]. In immunostained sections the concentration of $\mathrm{O} 157$ organisms in the lamina propria (dense colonies of uncountable bacteria) was striking when compared with their number amongst bacteria in the associated luminal contents, where typically sparsely scattered or no bacteria were seen. This suggested that the $\mathrm{O} 157$ bacteria were colonising the tissue more avidly than other bacteria present in the lumen, although spiral bacteria were also seen in the tissue in EM preparations. The lamina proprial lesion was seen only in lamb 2, in which the occurrence of observed epithelial abnormalities was higher, and in which the Campylobacter-like organisms were seen. Furthermore, pre-incubation in DMEM may have promoted expression of bacterial factors in the second lamb that were necessary for colonisation.

The role of $\mathrm{AE}$ lesions in persistent colonisation of ruminants by STEC O157:H7 remains undetermined. Any such lesions associated with persistence and a low level of excretion may be small, sparse, localised and possibly transient. The demonstration of STEC O157:H7-associated AE lesions in ruminating sheep establishes in principle the susceptibility to such adherence in the age group in which excretion is likely to be most significant from a public health perspective. In the present experiments, STEC O157:H7 induced small and sparse AE lesions when a small, well-defined area of the ovine bowel was subjected to a high bacterial concentration. The small size and paucity of the lesions found in the ligated loops resembles the situation in experimentally inoculated neonatal lambs $[14,55]$. Therefore, it is possible that current techniques are inadequate for detection of $\mathrm{AE}$ lesions when the search area extends throughout the large intestine of a naturally or deliberately infected and persistently colonised individual.

Other work with antibiotic resistance-labelled derivatives of these strains [55] indicates that strain 140065 may be more persistent in sheep following oral inoculation than the other three O157:H7 STEC used in the present study. It is interesting that the former strain proved capable of generating lesions in the colon loops of both animals used. Conversely, the formation of colon loop lesions by the other STEC strains, whose derivatives are relatively non-persistent in the young sheep model, indicates that $\mathrm{AE}$ capability, even if necessary for persistence, is not in itself sufficient. Consideration of the immune status of the animals was not given in this study. Li et al. [56] showed strong serological responses in man affected with STEC O157:H7 and it follows, therefore, that the immune status of the sheep may have played a role in limiting intimate adherence. Although the sheep were derived from STEC O157:H7-free stock, it remains possible that heterologous AEEC may induce cross-protective immunity. The ligated loop model may be an appropriate tool with which to test this hypothesis. 
We thank Dr K. White (anaesthetist), Mr S.J. Spencer (surgeon), Mr D. Clifford and Mr D. Sheehan (Animal Services Unit), Mr A. Skuse and Mrs V. Thomas (expert technical assistance with microscopy) and Mr J. Conibear (photography). This work was supported by the Department for Environment, Food and Rural Affairs (formerly the Ministry of Agriculture, Fisheries and Food, UK), project OZ0706.

\section{References}

1. Cryan B. Enterohaemorrhagic Escherichia coli. Scand J Infect Dis 1990; 22: 1-4.

2. Swinbanks D. Japan shuns radishes after 'possible link' to $E$. coli. Nature 1996; 382: 567.

3. Tarr PI. Escherichia coli O157:H7: clinical, diagnostic, and epidemiological aspects of human infection. Clin Infect Dis 1995; 20: $1-8$.

4. Jacewicz MS, Acheson DWK, Binion DG et al. Responses of human intestinal microvascular endothelial cells to shiga toxins 1 and 2 and pathogenesis of hemorrhagic colitis. Infect Immun 1999; 67: 1439-1444.

5. Louise CB, Obrig TG. Specific interaction of Escherichia coli O157:H7-derived Shiga-like toxin II with human renal endothelial cells. J Infect Dis 1995; 172: 1397-1401.

6. Sherman P, Soni R, Petric M, Karmali M. Surface properties of the Vero cytotoxin-producing Escherichia coli O157:H7. Infect Immun 1987; 55: 1824-1829.

7. Toth I, Cohen ML, Rumschlag HS et al. Influence of the 60megadalton plasmid on adherence of Escherichia coli $0157: \mathrm{H} 7$ and genetic derivatives. Infect Immun 1990; 58: 1223-1231.

8. Baehler AA, Moxley RA. Escherichia coli O157:H7 induces attaching-effacing lesions in large intestinal mucosal explants from adult cattle. FEMS Microbiol Lett 2000; 185: 239-242.

9. Phillips AD, Navabpour S, Hicks S, Dougan G, Wallis $T$, Frankel G. Enterohaemorrhagic Escherichia coli O157:H7 target Peyer's patches in humans and cause attaching/effacing lesions in both human and bovine intestine. Gut 2000; 47: 377-381.

10. Beery JT, Doyle MP, Schoeni JL. Colonization of chicken cecae by Escherichia coli associated with hemorrhagic colitis. Appl Environ Microbiol 1985; 49: 310-315.

11. Francis DH, Collins JE, Duimstra JR. Infection of gnotobiotic pigs with an Escherichia coli $\mathrm{O} 157: \mathrm{H} 7$ strain associated with an outbreak of hemorrhagic colitis. Infect Immun 1986; 51: 953-956.

12. Sherman P, Soni R, Karmali M. Attaching and effacing adherence of Vero cytotoxin-producing Escherichia coli to rabbit intestinal epithelium in vivo. Infect Immun 1988; 56: 756-761.

13. Dean-Nystrom EA, Bosworth BT, Cray WC, Moon HW Pathogenicity of Escherichia coli $\mathrm{O} 157: \mathrm{H} 7$ in the intestines of neonatal calves. Infect Immun 1997; 65: 1842-1848.

14. Wales AD, Pearson GR, Skuse AM et al. Attaching and effacing lesions caused by Escherichia coli O157:H7 in experimentally inoculated neonatal lambs. J Med Microbiol 2001; 50: 752-758.

15. Frankel G, Phillips AD, Rosenshine I, Dougan G, Kaper JB, Knutton S. Enteropathogenic and enterohaemorrhagic Escherichia coli: more subversive elements. Mol Microbiol 1998; 30: 911-921.

16. Burland V, Shao Y, Perna NT, Plunkett G, Sofia HJ, Blattner FR. The complete DNA sequence and analysis of the large virulence plasmid of Escherichia coli O157:H7. Nucleic Acids Res 1998; 26: 4196-4204.

17. Shere JA, Bartlett KJ, Kaspar CW. Longitudinal study of Escherichia coli $\mathrm{O} 157: \mathrm{H} 7$ dissemination on four dairy farms in Wisconsin. Appl Environ Microbiol 1998; 64: 1390-1399.

18. Mechie SC, Chapman PA, Siddons CA. A fifteen month study of Escherichia coli $\mathrm{O} 157: \mathrm{H} 7$ in a dairy herd. Epidemiol Infect 1997; 118: 17-25.

19. Besser TE, Hancock DD, Pritchett LC, McRae EM, Rice DH, Tarr PI. Duration of detection of fecal excretion of Escherichia coli O157:H7 in cattle. J Infect Dis 1997; 175: 726-729.

20. Kudva IT, Hatfield PG, Hovde CJ. Characterization of Escherichia coli $0157: \mathrm{H} 7$ and other Shiga toxin-producing $E$. coli serotypes isolated from sheep. J Clin Microbiol 1997; 35: 892-899.

21. Griffin PM, Tauxe RV. The epidemiology of infections caused by Escherichia coli $\mathrm{O} 157: \mathrm{H7}$, other enterohemorrhagic E. coli, and the associated hemolytic uremic syndrome. Epidemiol Rev 1991; 13: 60-98.

22. Chapman PA. Sources of Escherichia coli O157 and experiences over the past 15 years in Sheffield, UK. $J$ Appl Microbiol 2000; 88 Suppl: 51S-60S.

23. Hancock DD, Besser TE, Kinsel ML, Parr PI, Rice DH, Paros MG. The prevalence of Escherichia coli O157.H7 in dairy and beef cattle in Washington State. Epidemiol Infect 1994; 113: 199-207.

24. Laegreid WW, Elder RO, Keen JE. Prevalence of Escherichia coli O157:H7 in range beef calves at weaning. Epidemiol Infect 1999; 123: 291-298.

25. Elder RO, Keen JE, Siragusa GR, Barkocy-Gallagher GA, Koohmaraie M, Laegreid WW. Correlation of enterohemorrhagic Escherichia coli $\mathrm{O} 157$ prevalence in feces, hides, and carcasses of beef cattle during processing. Proc Natl Acad Sci USA 2000; 97: 2999-3003.

26. Smith D, Blackford M, Younts S et al. Ecological relationships between the prevalence of cattle shedding Escherichia coli O157:H7 and characteristics of the cattle or conditions of the feedlot pen. J Food Prot 2001; 64: 1899-1903.

27. Wells JG, Shipman LD, Greene KD et al. Isolation of Escherichia coli serotype O157:H7 and other Shiga-liketoxin-producing E. coli from dairy cattle. J Clin Microbiol 1991; 29: 985-989.

28. Zhao T, Doyle MP, Shere J, Garber L. Prevalence of enterohemorrhagic Escherichia coli O157:H7 in a survey of dairy herds. Appl Environ Microbiol 1995; 61: 1290-1293.

29. Kudva IT, Hatfield PG, Hovde CJ. Escherichia coli O157:H7 in microbial flora of sheep. J Clin Microbiol 1996; 34: 431-433.

30. Cray WC, Moon HW. Experimental infection of calves and adult cattle with Escherichia coli O157:H7. Appl Environ Microbiol 1995; 61: 1586-1590.

31. Wray C, McLaren IM, Randall LP, Pearson GR. Natural and experimental infection of normal cattle with Escherichia coli O157. Vet Rec 2000; 147: 65-68.

32. Cornick NA, Booher SL, Casey TA, Moon HW. Persistent colonization of sheep by Escherichia coli O157:H7 and other E. coli pathotypes. Appl Environ Microbiol 2000; 66: 49264934.

33. Kudva IT, Hatfield PG, Hovde CJ. Effect of diet on the shedding of Escherichia coli $\mathrm{O} 157: \mathrm{H} 7$ in a sheep model. Appl Environ Microbiol 1995; 61: 1363-1370.

34. Dean-Nystrom EA, Bosworth BT, Moon HW, O'Brien AD. Escherichia coli O157:H7 requires intimin for enteropathogenicity in calves. Infect Immun 1998; 66: 4560-4563.

35. Dean-Nystrom EA, Bosworth BT, O’Brien AD, Moon HW. Bovine infection with Escherichia coli O157:H7. In: Stewart CS, Flint HJ (eds) E. coli O157 in farm animals. Wallingford, CAB International. 1999: 51-58.

36. Smith HW, Halls S. Observations by the ligated intestinal segment and oral inoculation methods on Escherichia coli infections in pigs, calves, lambs and rabbits. J Pathol Bacteriol 1967; 93: 499-529.

37. Moon HW, Whipp SC, Argenzio RA, Levine MM, Giannella RA. Attaching and effacing activities of rabbit and human enteropathogenic Escherichia coli in pig and rabbit intestines. Infect Immun 1983; 41: 1340-1351.

38. Stevens MP, Marches O, Campbell $\mathrm{J}$ et al. Intimin, tir, and shiga toxin 1 do not influence enteropathogenic responses to shiga toxin-producing Escherichia coli in bovine ligated intestinal loops. Infect Immun 2000; 70: 945-952.

39. Pearson GR, Bazeley KJ, Jones JR et al. Attaching and effacing lesions in the large intestine of an eight-month-old heifer associated with Escherichia coli O26 infection in a group of animals with dysentery. Vet Rec 1999; 145: 370-373.

40. Dibb-Fuller MP, Best A, Stagg DA, Cooley WA, Woodward MJ. An in-vitro model for studying the interaction of Escherichia coli $0157: \mathrm{H} 7$ and other enteropathogens with bovine primary cell cultures. J Med Microbiol 2001; 50: 759769.

41. Knutton S, Baldwin T, Williams PH, McNeish AS. Actin accumulation at sites of bacterial adhesion to tissue culture cells: basis of a new diagnostic test for enteropathogenic and enterohemorrhagic Escherichia coli. Infect Immun 1989; 57: 1290-1298.

42. White K, Taylor P. Anaesthesia in sheep. In Practice 2000; 22: $126-135$.

43. Wales AD, Clifton-Hadley FA, Cookson AL et al. Experi- 
mental infection of six-month old lambs with Escherichia coli O157:H7. Vet Rec 2001; 148: 630-631.

44. Janke BH, Francis DH, Collins JE et al. Attaching and effacing Escherichia coli infection as a cause of diarrhea in young calves. J Am Vet Med Assoc 1990; 96: 897-901.

45. Knutton S, Adu-Bobie J, Bain C, Phillips AD, Dougan G, Frankel G. Down regulation of intimin expression during attaching and effacing enteropathogenic Escherichia coli adhesion. Infect Immun 1997; 65: 1644-1652.

46. Ogierman MA, Paton AW, Paton JC. Up-regulation of both intimin and eae-independent adherence of shiga toxigenic Escherichia coli $\mathrm{O} 157$ by ler and phenotypic impact of a naturally occurring ler mutation. Infect Immun 2000; 68: $5344-5353$.

47. Tzipori S, Karch H, Wachsmuth KI et al. Role of a 60megadalton plasmid and Shiga-like toxins in the pathogenesis of infection caused by enterohemorrhagic Escherichia coli O157:H7 in gnotobiotic piglets. Infect Immun 1987; 55: 3117 3125.

48. Richardson SE, Rotman TA, Jay $\mathrm{V}$ et al. Experimental verocytotoxemia in rabbits. Infect Immun 1992; 60: $4154-$ 4167.

49. Mobassaleh M, Donohue-Rolfe A, Jacewicz M, Grand RJ, Keusch GT. Pathogenesis of shigella diarrhea: evidence for a developmentally regulated glycolipid receptor for shigella toxin involved in the fluid secretory response of rabbit small intestine. J Infect Dis 1988; 157: 1023-1031.

50. Williams Smith H, Green P, Parsell Z. Vero cell toxins in Escherichia coli and related bacteria: transfer by phage and conjugation and toxic action in laboratory animals, chickens and pigs. J Gen Microbiol 1983; 129: 3121-3137.

51. Kudva IT, Hunt CW, Williams CJ, Nance UM, Hovdew CJ. Evaluation of dietary influences on Escherichia coli O157:H7 shedding by sheep. Appl Environ Microbiol 1997; 63: 3878 3886.

52. Hoey DE, Currie C, Else RW et al. Expression of receptors for verotoxin 1 from Escherichia coli O157 on bovine intestinal epithelium. J Med Microbiol 2002; 51: 143-149.

53. Jopp A, Orr MB. Enteropathy and nephropathy associated with "winter scour" in hoggets. NZ Vet $J$ 1980; 28: 195.

54. Tzipori S, Wachsmuth KI, Chapman C et al. The pathogenesis of hemorrhagic colitis caused by Escherichia coli $\mathrm{O} 157: \mathrm{H} 7$ in gnotobiotic piglets. $J$ Infect Dis 1986; 154: 712-716.

55. Wales AD, Pearson GR, Roe JM et al. Preliminary observations on $E$. coli $\mathrm{O} 157: \mathrm{H} 7$ in sheep. In: Verocytotoxigenic $E$. coli in Europe: 5. Epidemiology of Verocytotoxigenic E. coli. Dublin, Teagasc. 2001.

56. Li Y, Frey E, Mackenzie AMR, Finlay BB. Human response to Escherichia coli $\mathrm{O} 157: \mathrm{H} 7$ infection: antibodies to secreted virulence factors. Infect Immun 2000; 68: 5090-5095. 